\title{
Finding the time
}

\section{The scientific struggle to bring the world's clocks into line.}

\author{
Einstein's Clocks and Poincaré's \\ Maps: Empires of Time \\ by Peter Galison \\ W. W. Norton: 2003. 370 pp. $\$ 23.95$ \\ Sceptre: 2003. 114.99

\section{Jeremy Gray}

The challenge of synchronizing clocks around the world, and accurately determining longitudes, required the construction of a great net of cables, often with considerable difficulty. With similar energy, scientists and politicians fought to establish the zero meridian and even the units of time (the French lost both contests, so Greenwich is the zero meridian and time was not decimalized). Peter Galison tells this tale in a tremendous yarn that takes up the largest of the three parts in his new book, Einstein's Clocks and Poincarés Maps. Henri Poincaré was a prominent figure in these tumultuous events, and Galison argues convincingly, backed by a great deal of hitherto neglected information, that he was a leading product of his formative institution, the Ecole Polytechnique in Paris.

But what does this tell us about time? Newton had believed what most people involved in the creation of the global network of clocks believed, namely that the Universe is like a stage on which it makes sense to be able to say precisely when two separate events take place. The great struggle to create a single empire of time in which it was possible to say anywhere in the world what the time was (as recorded on a clock in London) was a move to put Newton's idea of time into operation. Observers in London, Paris and New York could all agree that it was, say, 17:00 (although local times might differ). This process is somewhat arbitrary, but the concept of time underpinning it is fundamentally Newton's, shorn, in Poincaré's view, of some illegitimate intuitions.

On this conception, a fast-moving observer can read off the time by simply looking at standardized clocks as he passes them. But that is not what can be done. Einstein's shattering insight into time is that Newton's universal time does not make sense. Observers in a state of constant relative motion with respect to each other do not keep the same time: their clocks beat at different rates.

By 1900, physicists knew that something was amiss in their theories. Prominent among them was Hendrik Lorentz, who in 1904 introduced a trick to resolve discrepancies in the theory of the moving electron. This was the idea of local time. Poincaré showed in 1905 that Lorentz's local time could be interpreted as the time kept by an imaginary clock moving with the electron as it beat against the ether. In the same way, lengths of objects were supposed to contract as they moved relative to the ether. By 1912, Poincaré had come close to accepting Einstein's theory, but he regarded it as a convention, to be accepted or rejected on utilitarian grounds, and never gave it the force that the iconoclastic younger man did.

This shift from one conception of time to another is the second theme of the book, and it is less successful. Galison would have us believe that empire time was radically different from newtonian time. He writes: "Newton's absolute, theological time had no place ... Engineering common time stood where God's absolute time had been," but this seems unconvincing. Galison also downplays the details of the intense scientific debate, which was well described in Arthur I. Miller's Albert Einstein's Special Theory of Relativity (Addison-Wesley, 1980), in order to give salience to the technological and political factors he has identified. In so doing he pushes Poincaré and Einstein closer together than they were, stressing their involvement in the world of clocks and measurements, and diminishing the radical nature of Einstein'sideas.

Einstein is presented here as a serious and talented worker in the patent office. This is surely an improvement on his portrayal, sometimes fostered by Einstein himself, as an other-worldly academic, although Lewis Pyenson has already described Einstein as an enthusiastic worker in the patent office in The Young Einstein (Adam Hilger, 1985). Perhaps Einstein's daily working life contributed to his insistence on clocks and the measurement of time in his famous paper of 1905 in which he introduced special relativity. However, he is also described as a radical and an iconoclast. The inevitable question is then to decide what weight to attach to these different factors, and Galison refuses to address the matter.

Instead, he has written a methodological final chapter arguing for the inseparability of all the factors that he has introduced, from the grittiest to the most ethereal. He argues that Poincaré in particular was situated at the intersection of three arcs, namely developments in physics, telegraphy and philosophy. Einstein was likewise at a triple intersection, of a slightly different kind. We can accept that it is not easy to situate scientific discovery in a richly overlapping set of contexts, and that conclusions should be tentative, but by marginalizing the strictly scientific debate, the implication that the other arcs carry significant weight is allowed to slip through too easily. This matters greatly when discussing Poincaré, because it is often argued that his capacity to move between mathematics, physics and philosophy often weakened his insights into physics.

The logic of Galison's position is surely

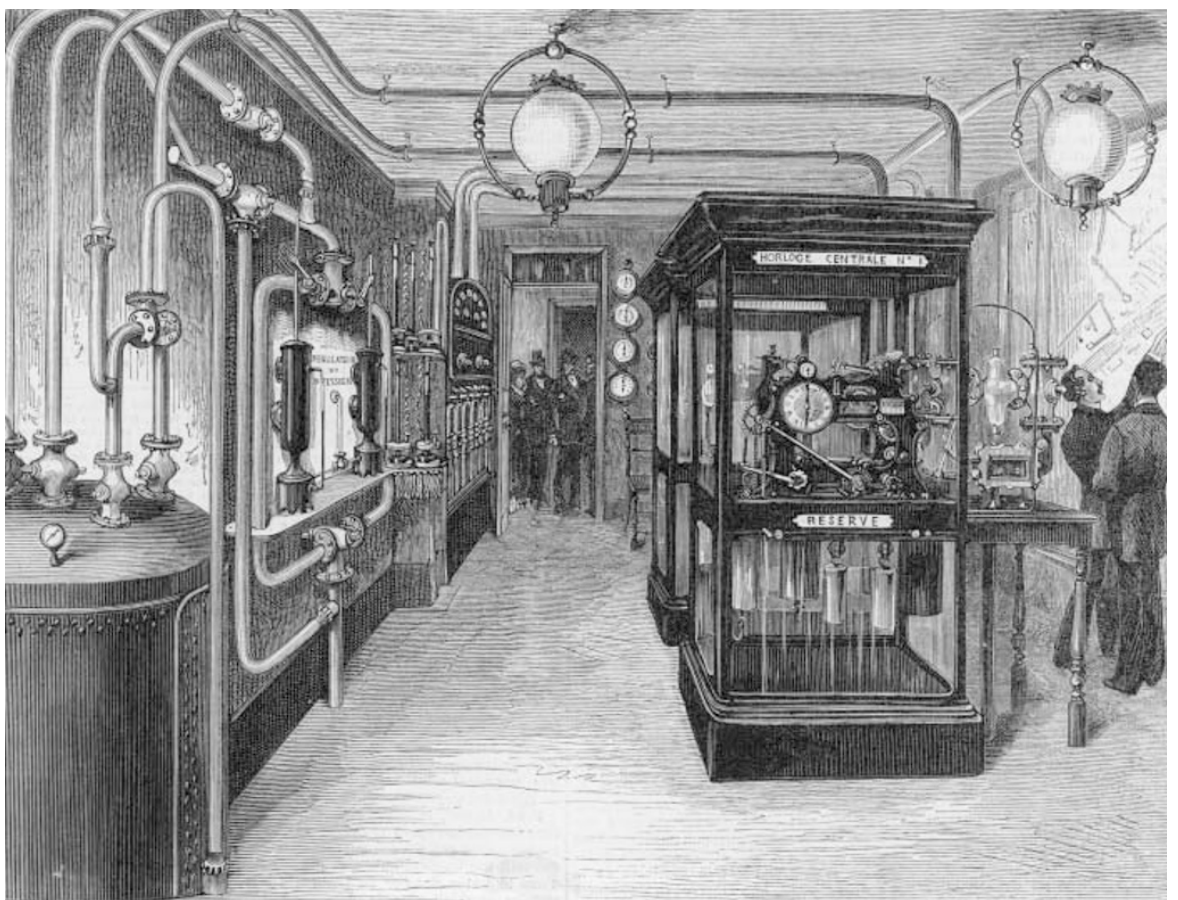

Keeping time: the control room at the Rue du Télégraphe in Paris synchronized the city's clocks. 
that, if empire time is by its nature different from newtonian time, then one might expect someone heavily committed to the establishment of empire time to differ from those habituated to newtonian time. Poincaré should differ from Lorentz, at least, and be closer to Einstein. If empire time was simply understood as being newtonian time put into practice, then Poincaré would resemble Lorentz and differ from Einstein, who believed that time had to be defined by means of clocks (and not merely captured).

Perhaps Poincaré's deep intellectual and political immersion in the creation of empire time with its global sense of simultaneity worked against him when he had the chance to reformulate time as Einstein did, and even to accept it afterwards as, steadily, his contemporaries did. But there are other possible explanations and such inferences are risky. Ultimately, the methodological sophistication in this book may not deliver what its author hopes, but the wealth of information it contains is surely stimulating.

Jeremy Gray is at the Centre for the History of the Mathematical Sciences, Faculty of Mathematics and Computing, Open University, Milton Keynes MK7 6AA, UK.

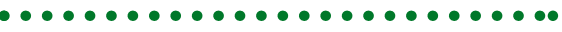 Fountain of hype}

\section{Merchants of Immortality: Chasing the Dream of Human Life Extension \\ by Stephen Hall \\ Houghton Mifflin: 2003. 440 pp. \$25}

\section{S. Jay Olshansky}

One can imagine an alchemist some 2,000 years ago weaving a tale for the investors and politicians of his day. They cling to every word as he tells them how the properties of immortality thought to exist for gold could be transferred to humans by ingesting minute quantities of the rare metal. According to the alchemist, 'science' is only 10-20 years away from a breakthrough that would give rise to immortality for those willing to invest. All that is needed is money and time to figure out the recipe.

Such merchants of immortality have been spinning their tale since time immemorial. So it is not surprising that in today's rapidly ageing society, where medical technology can manufacture survival time, there is an abundance of scientists and longevity salesmen (on occasion they are one and the same) who seek lucre from the promise of a longer and healthier life. Are the modern immortality salesmen on the trail of the genuine fountain of youth, or are contemporary investors and consumers of the anti-ageing industry being duped, like countless before them? In Merchants of Immortality, Stephen Hall provides the answer.

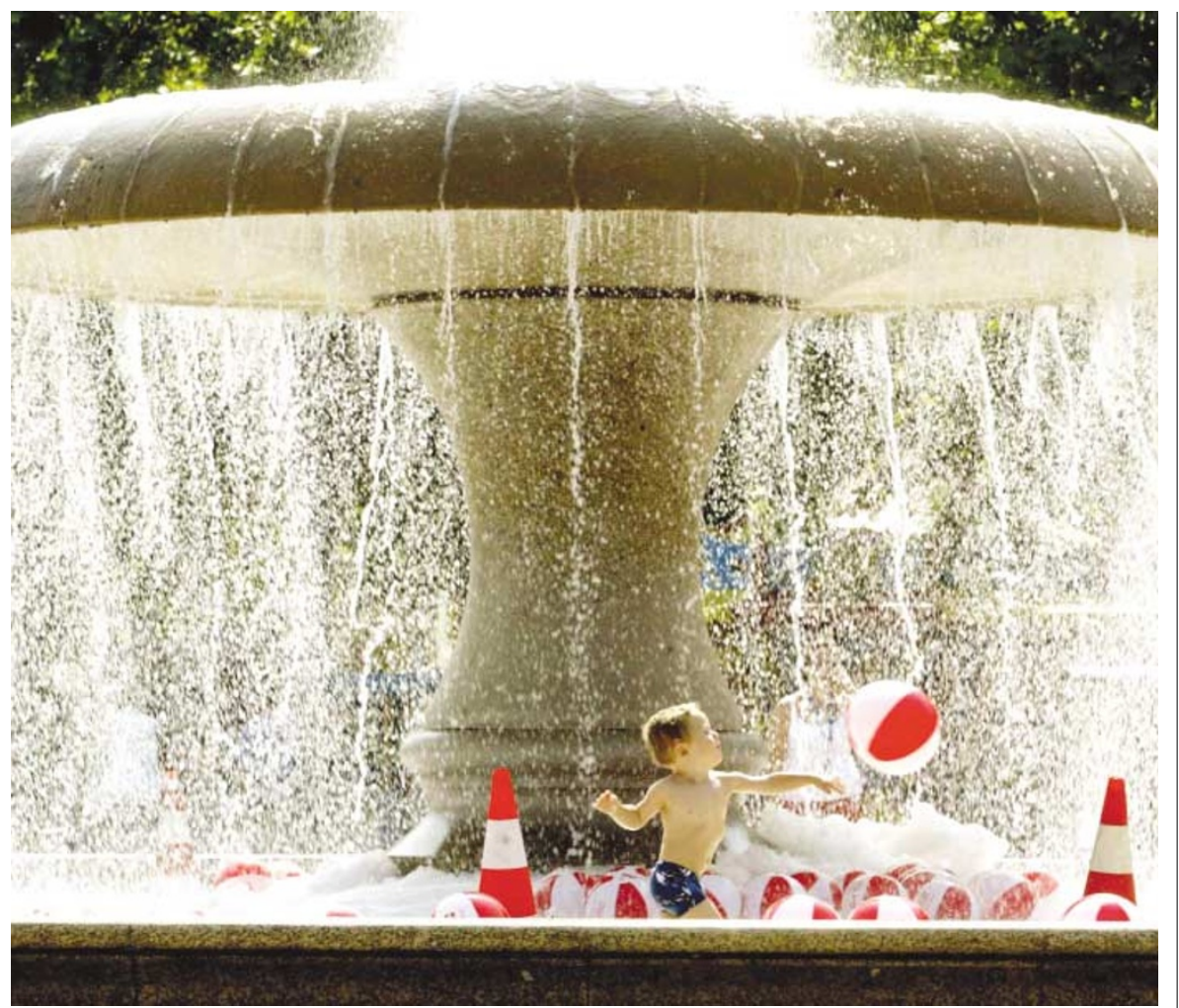

Making a splash: immortalists make dramatic claims that there really is a fountain of youth.

Hall begins with an account of Leonard Hayflick's discovery that some cells have a limited capacity to replicate. The irony is that Hayflick, who is the father of biogerontology, is also the most ardent voice of authority against the immortalists, yet his view on the topic is barely mentioned. Instead Hall goes into detail about Hayflick's battle with the government over a human cell line he developed that was later used to produce life-saving vaccines.

The one scientist who appears repeatedly throughout the book as the most ardent merchant of immortality is Michael West, the budding priest turned scientist and entrepreneur who wrote about the longevityenhancing effects of telomerase, cloning and embryonic stem cells. Hall takes issue with West's recipe for immortality, which has lured in a bevy of investors who were all too willing to have a financial stake in the fountain of youth.

Several chapters are devoted to similar tales of scientists-turned-entrepreneurs. They are mainly fascinating but sad stories of how money both corrupts and enhances modern science. But it is exactly this kind of entrepreneurship that, despite its potential to corrupt and the numerous roadblocks placed before science by politics and ignorance, has the potential to create a new field of regenerative medicine from recent developments regarding embryonic and adult stem cells.

It is often difficult for scientists to see the importance of their work and its relevance in a world where social norms and ethics can mesh and clash at the same time. There is no area of research where this dichotomy is more evident than studies of ageing. Hall pays what seems at first to be an inordinate amount of attention to the politics behind cloning and the use of embryonic and adult stem cells, but it soon becomes evident how debates about abortion and rightto-life issues have a direct influence on funding for research. He stresses that the politics of science in this case is not about the quest for immortality or the battle against ageing itself, but about efforts to combat disease.

Hall makes the case that the modern search for the fountain of youth, through the study of telomeres and embryonic and adult stem cells, is built on a house of cards. It is a mirage, he says, offering everlasting (or at least much longer) life, and has been placed on the horizon by a handful of scientists who seek wealth by making some exaggerated claims. What may realistically be on offer is not an extended lifespan but rather a healthier old age. Hall mentions scientists (including Hayflick) who have challenged the remarkable claims of the immortalists. But given the tales being spun and the pot of money awaiting a victor in the quest for a fountain of youth, it is no surprise that he has chosen to focus on the immortalists.

The field of ageing research should be grateful to Hall for applying his journalistic wizardry to the story of the modern quest for immortality. In this book he captures the drama, excitement, competition and 